http://jmscr.igmpublication.org/home/ ISSN (e)-2347-176x ISSN (p) 2455-0450 crossref DOI: https://dx.doi.org/10.18535/jmscr/v8i4.54

Journal Of Medical Science And Clinical Research

\title{
Our Experience in Treatment of Colorectal Cancers in KGH, Visakhapatnam
}

\author{
Authors \\ Chintagada Jayaraj ${ }^{1}$, Buddha Kanaka Mahalakshmi ${ }^{2}$, Simhadri Uday Kiran ${ }^{3}$, \\ Murali Manohar Deevi ${ }^{4}$, Ginni Vijay Sainath Reddy ${ }^{5}$, Ginjupalli Saichand ${ }^{6}$, \\ Sivaram Shashank Yeeli ${ }^{7}$, Potireddy Yaswanth Reddy \\ ${ }^{1}$ Professor and HOD, General Surgery \\ ${ }^{2}$ Assistant Professor, General Surgery \\ ${ }^{3,4,5,6,7,8}$ Post Graduate, General Surgery
}

\begin{abstract}
Background: Colorectal cancers are the second most common cause of death in the UK. It is usually caused due to mutations of APC, K-ras, p53 genes. Patients present more commonly with bleeding per rectum or obstructive symptoms. Colonoscopy is the investigation of choice. Staging is by spiral CT. The aim of the study is to calculate the age-wise incidence, common presenting symptoms, and treatment strategies employed in our setup.

Material and Methods: A retrospective study was conducted on 30 cases of colorectal cancer in the Department of General Surgery, King George Hospital, Visakhapatnam, from June 2018 to June 2019. Patients presenting with symptoms suggestive of colorectal cancer were admitted, investigated using routine investigations, colonoscopy, and CT scan, and operated during this period. Factors studied were incidence, presenting complaints, and treatment options.

Results: Twenty cases were between the age group 45-60, 8 cases were above 60 years, and 2 cases between the age group 40-45. Twenty-five cases presented with bleeding per rectum, anemia, and 5 cases presented with increased frequency and pain during defecation. The most common histology was moderately differentiated adenocarcinoma. All the patients underwent resection of the primary tumor with regional lymphadenectomy.

Conclusion: The incidence of colorectal cancer has risen. The risk of incidence is more in the age group 45-60 years with bleeding per rectum as the common presenting complaint. Increasing awareness regarding the risk factors and symptoms is needed for early detection. Early diagnosis with prompt screening techniques helps to reduce the mortality rate.
\end{abstract}

\section{Introduction}

Colorectal cancers are the second most common cause of death in the UK. It is usually caused due to mutations of APC, K-ras, p53 genes. They arise from adenomatous polyps after a sequence of mutations called adenoma-carcinoma sequence. $70 \%$ of the cancers are left-sided ${ }^{(1)}$. 
Risk factors include red meat, high fat, and low fiber diet, which increases the transit time and thus exposure of colonic mucosa to carcinogens. Patients present more commonly with bleeding per rectum or obstructive symptoms ${ }^{(2)(4)}$.

Colonoscopy is the investigation of choice. Staging is by spiral CT. Early screening is by fecal occult blood testing for age 60-69 years, followed by colonoscopy in suspicious cases $^{(1)(4)(5)}$. Aim of the study is to suggest that there has been an increase in the distribution of colorectal cancer even in the Indian population where high carbohydrate and high fiber diet are consumed.

\section{Aims and Objectives}

1. To identify the population at risk of developing colorectal cancers.

2. To identify the most common presenting symptoms and stage of presentation.

\section{Material and Methods}

A retrospective study was conducted on 30 cases of colorectal cancer in the Department of General Surgery, King George Hospital, Visakhapatnam, from June 2018 to June 2019. Patients presenting with symptoms suggestive of colorectal cancer were admitted, investigated using routine investigations, colonoscopy, and CT scan, and operated during this period. Factors studied were incidence among age, sex and demography, presenting complaints, stage of presentation, and treatment options available in our setup. Based on the tumor resectability, treatment options like resection of primary tumor or metastasectomy, along with resection of the primary tumor or palliative diversion, were considered.

\section{Inclusion Criteria}

1) Males and females above 18 years.

2) Patients with colorectal cancer confirmed on histopathology are included.

\section{Results}

Higher incidence of colorectal cancers was seen in the age group of $45-60$ years $(66.6 \%)$, followed by $>60$ years $(26.6 \%)$ and $30-45$ years $(6.6 \%)$.

The urban population is at a higher risk of developing colorectal cancers due to exposure to hazardous food habits contributing to around $76.6 \%$ compared to the rural community $(24.4 \%)$.

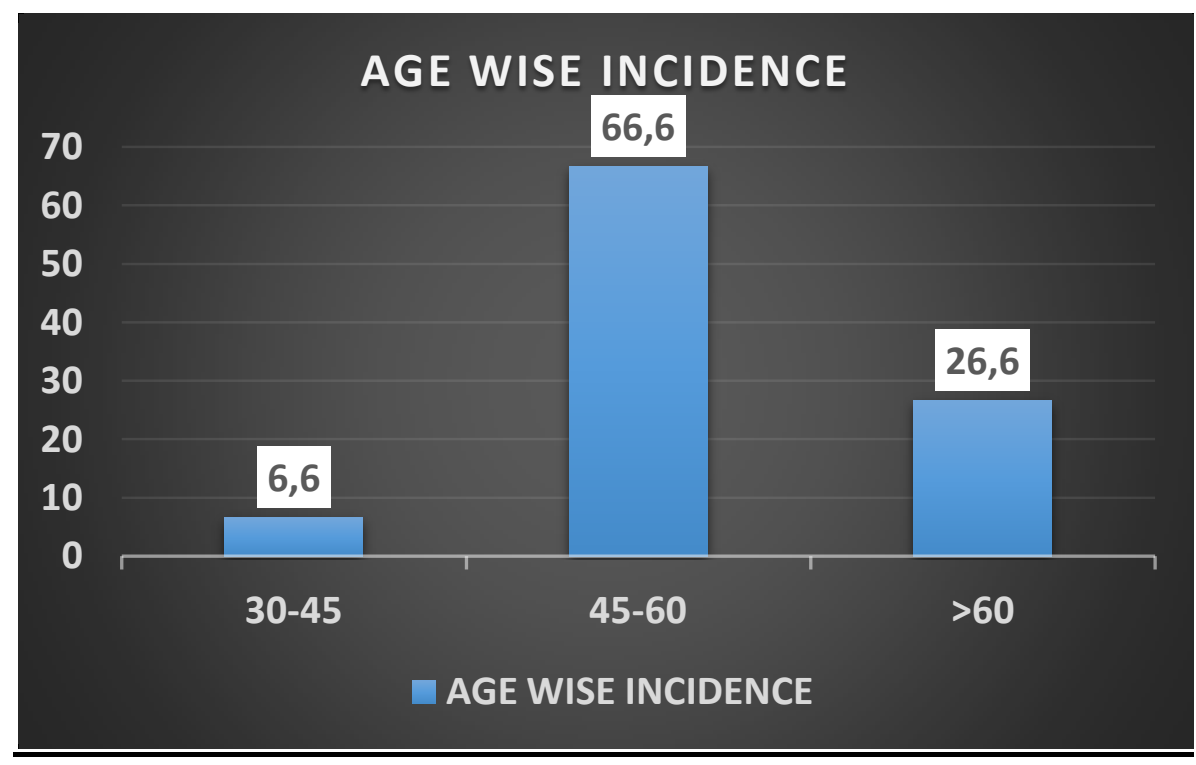




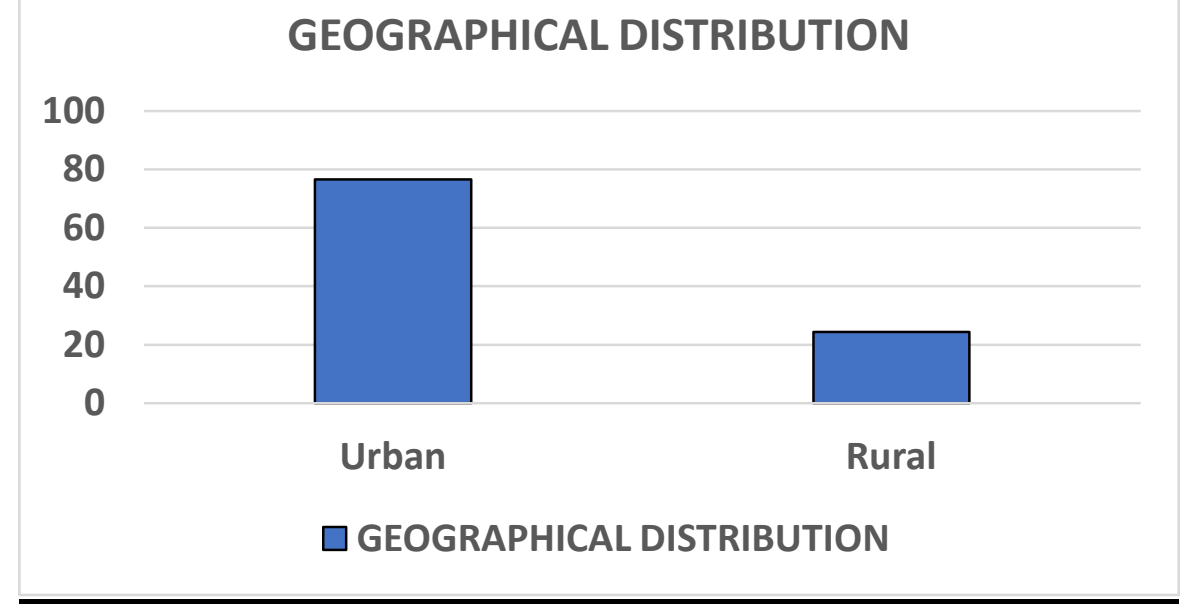

$67 \%$ of the patients presented with the chief complaint of bleeding per rectum and anemia, while $20 \%$ presented with painful defecation and increased frequency. $13 \%$ presented to the emergency with symptoms of obstruction.
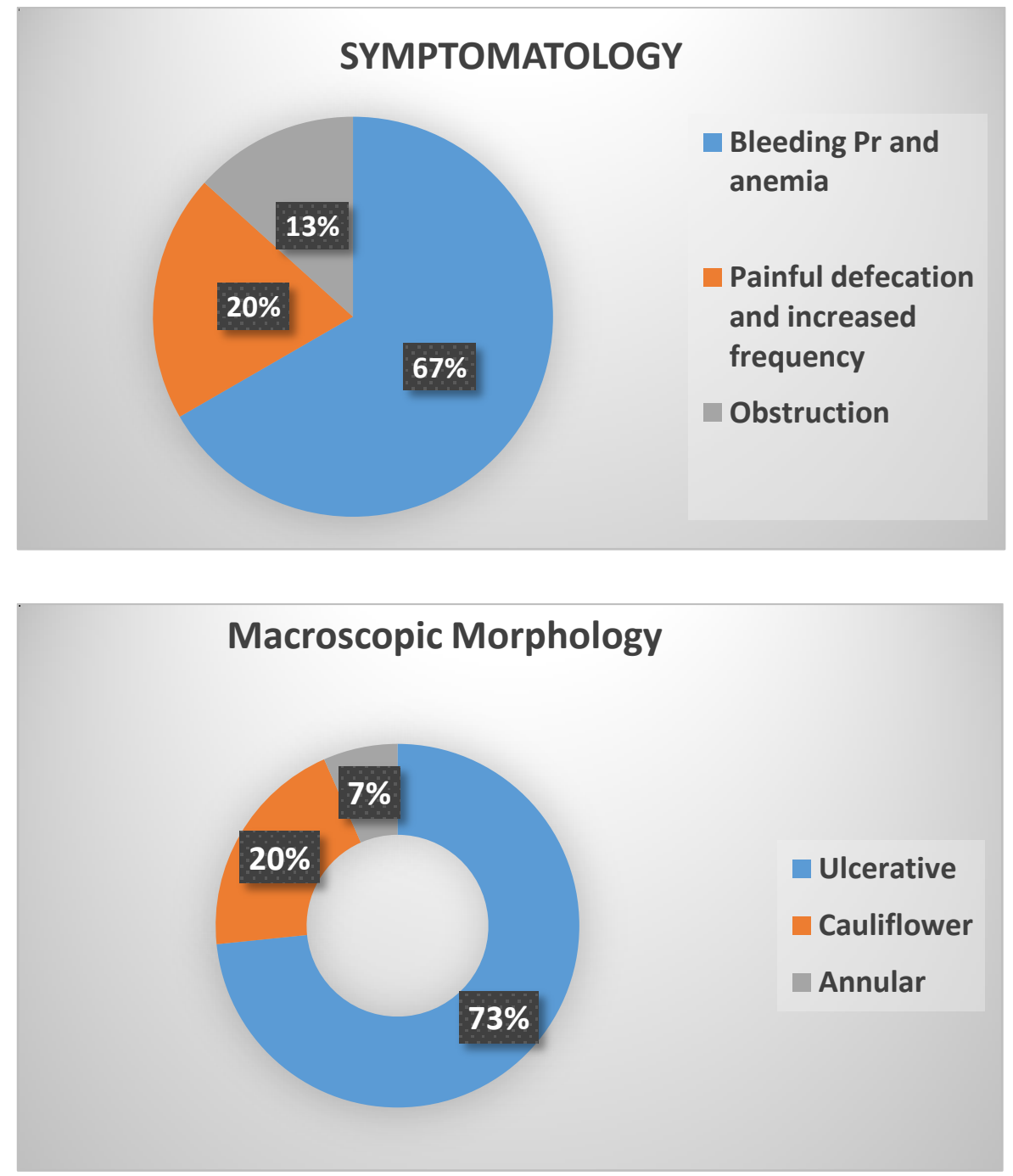
On colonoscopy, there was evidence of ulcerative growth in 22 cases and cauliflowerlike growth in 6 cases and annular growth in 2 cases.

All the patients were admitted on op basis except 4 cases who presented to emergency with symptoms of obstruction.

In 20 cases, the tumor was located in the rectum, rectosigmoid junction in 6 cases, and in ascending colon in 4 cases.

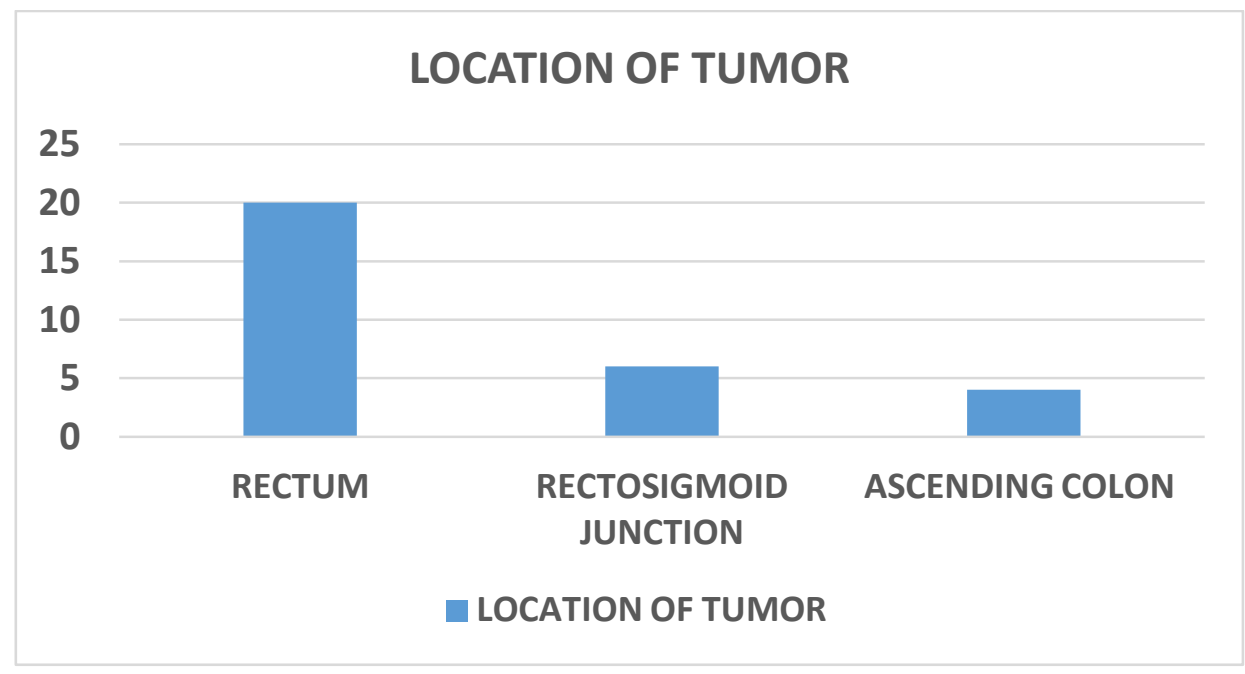

\section{Histopathology}

Histopathological diagnosis was moderately differentiated adenocarcinoma in 20 cases and poorly differentiated in 7 cases and welldifferentiated in 3 cases.

16 patients presented at stage 2, 6 patients in stage 4,5 patients in stage 3 , and 3 cases at stage 1.

\section{STAGES AT PRESENTATION}

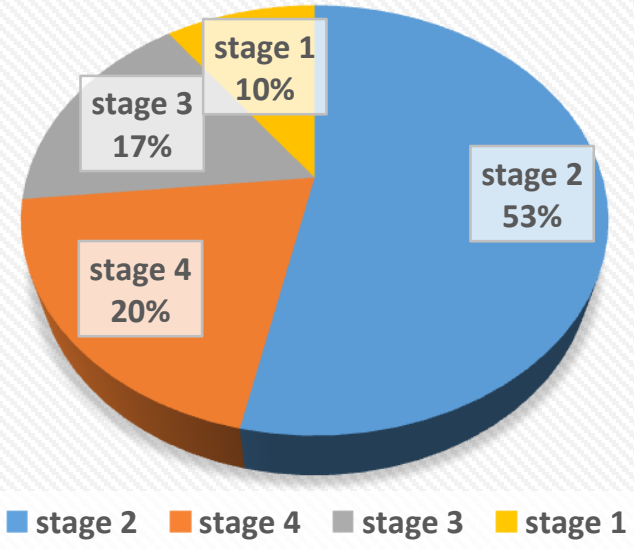




\section{Treatment}

Resection of the primary tumor was carried out in the patients diagnosed with stage 1, 2, and 3 (24 patients). Metastasectomy (resectable liver metastasis) along with resection of the primary tumor was done in 2 patients. Four patients with extensive spread disease were subjected to palliative diversion. Administration of postoperative chemotherapy was increased in patients with stages 1,2 , and 3 . Six patients diagnosed with stage 4 were subjected to palliative chemotherapy.

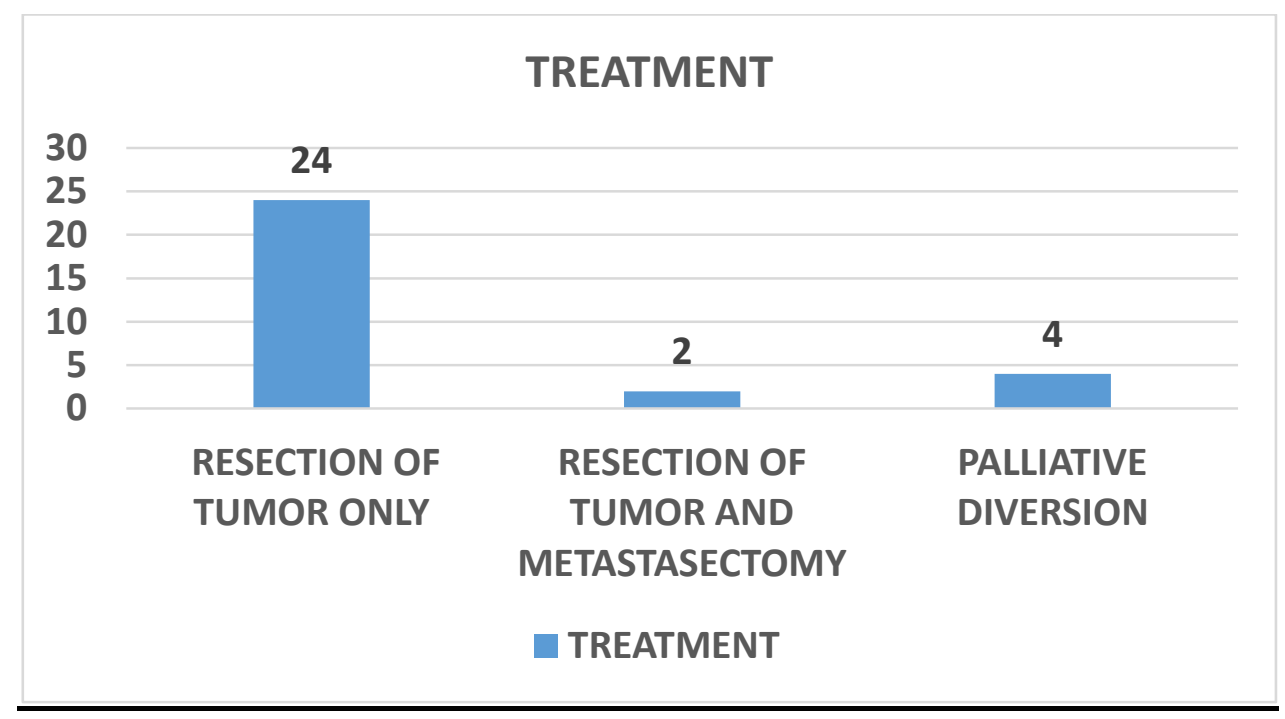

\section{Discussion}

Colorectal cancers have been on the rising trends these days due to the change in lifestyle and food habits. Males are affected more than females. It is the third most commonly diagnosed cancer in males. Incidence and death rates for colorectal cancer increases with age. It is caused due to mutations of APC, p53, K-ras genes. The most common presenting symptoms are bleeding per rectum, pain, and increased the frequency of defecation. Other symptoms include anemia, weight loss. $20 \%$ of the cases present late. An increase in the use of colonoscopy and CT scans has helped to detect early. Following investigations help in early diagnosis based on family history and symptomatology:

1) Fecal occult blood testing annually

2) Colonoscopy or Sigmoidoscopy

3) CT scan to know the extent of the disease

4) PET and MRI can be used in some instances.
In a similar study by Shinya Munakata et al., the mean age group affected was 75 years $^{(1)}$, whereas, in this present study, the higher incidence was seen in 45-60 years of age (66.6\%).

In the present study, most of the patients presented in stage $2(53 \%)$, followed by stage $4(20 \%)$. In research by Shinya Munakata et al. 85 cases presented in stage 2 and 63 cases presented in stage $3^{(1)}$.

In the present study, the most common location of the tumor is in the rectum ( 20 cases), followed by a rectosigmoid junction (6 cases). In a study by Shinya Munakata et al., the location of the tumor is as follows-Cecum/Ascending/Transverse/ Descending/Sigmoid)-16/36/16/14/66 ${ }^{(1)}$. 
HISTOLOGICAL VARIATION

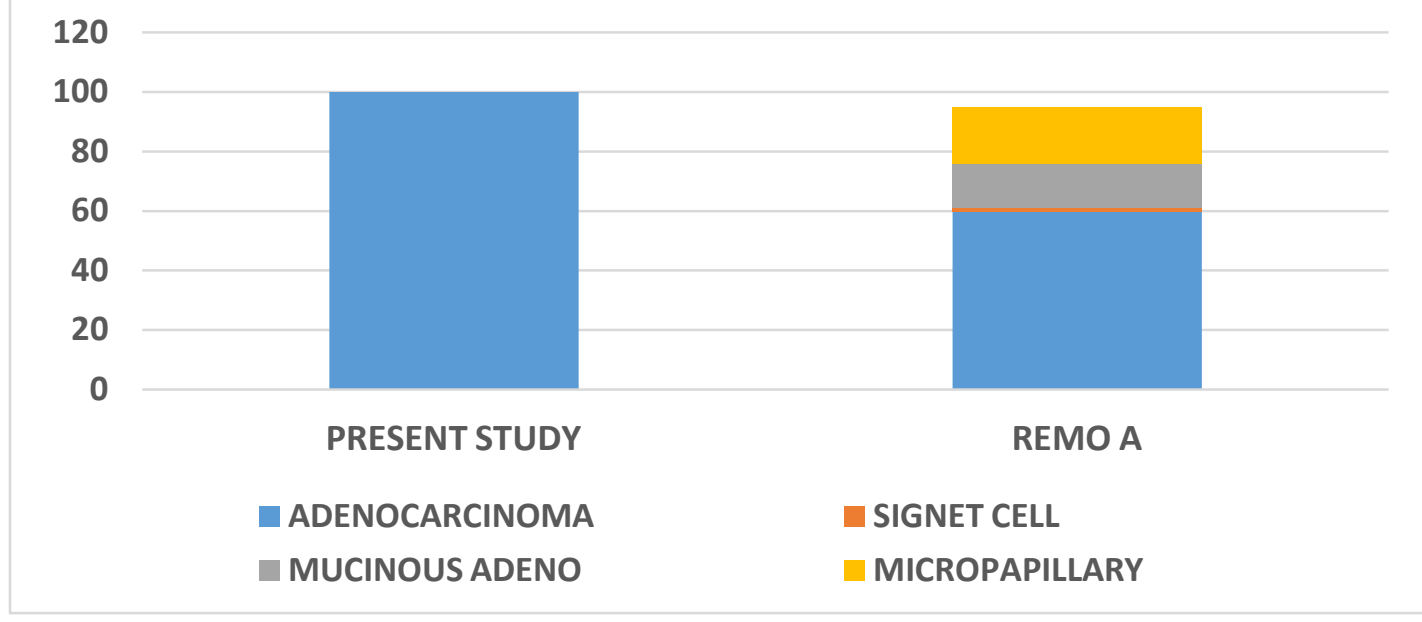

In this study, 24 cases (stage 1, 2, 3) were subjected to curative resection. Curative therapy includes resection of the primary tumor and regional lymphadenectomy. Chemotherapy with oxaliplatin, leucovorin, 5-fluorouracil was considered in this study. The most common site of primary in the present study is the rectum, compared to the studies of western countries where the common site is colon (mostly leftsided)

\section{Conclusion}

The incidence of colorectal cancer has risen. The risk of incidence is more in the age group 45-60 years with bleeding per rectum as the common presenting complaint. This increase in incidence seen in the urban population due to exposure to high fat and low fiber diet emphasizes the importance of lifestyle modification. Early diagnosis with prompt screening techniques helps to reduce the mortality rate. Metastasectomy is done if resectable liver metastasis is present, which improves Survival.Palliative chemotherapy needs to be given in the presence of widespread disease, which can downstage the tumor and make it resectable.

\section{References}

1. Munakata, S., Murai, Y., Koiuzumi, A., Kato, H., Yamamoto, R., Ueda, S., ... Sato, K. (2018). Long-term outcomes of colorectal cancer patients with and without malignant large-bowel obstruction.

Colorectal Cancer, 7(2), CRC04. doi:10.2217/crc-2018-0001.

2. An overview of 25 years of incidence, treatment and outcome of colorectal cancer patients.Nelleke P.M. Brouwer, 1 Amanda C.R.K. Bos, 2 Valery E.P.P. Lemmens, 2 , 3 Pieter J. Tanis, 4 Niek Hugen, 1 Iris D. Nagtegaal, 5 Johannes H.W. de Wilt, 1 and Rob H.A. Verhoeven 1 ,

3. Lemmens $\mathrm{V}$, van Steenbergen $\mathrm{L}$, Janssen- Heijnen $M$, et al. Trends in colorectal cancer in the south of The Netherlands 1975- 2007: rectal cancer survival levels with colon cancer survival. Acta Oncol2010;49:784-96. [PubMed] [Google Scholar]

4. Toes- Zoutendijk E, van Leerdam ME, Dekker E, et al. Real- time monitoring of results during first year of dutch colorectal cancer screening program and optimization by altering fecal immunochemical test cut- off levels. Gastroenterology 2016;154 (4):767-777. [PubMed] [Google Scholar]

5. Bokkerink GM, Buijs EF, de Ruijter W, et al. Improved quality of care for patients undergoing an abdominoperineal excision for rectal cancer. Eur J Surg Oncol 2015; 41:201-7. [PubMed] [Google Scholar]

6. Bonjer HJ, Deijen CL, Haglind E. A randomized trial of laparoscopic versus open surgery for rectal cancer. $\mathrm{N}$ Engl $\mathrm{J}$ 
Med 2015;373:194. [PubMed] [Google Scholar]

7. Kapiteijn E, Marijnen CA, Nagtegaal ID, et al. Preoperative radiotherapy combined with total mesorectal excision for resectable rectal cancer. $\mathrm{N}$ Engl $\mathrm{J}$ Med 2001;345:638-46. [PubMed] [Google Scholar]

8. Buunen M, Veldkamp R, Hop WC, et al. Survival after laparoscopic surgery versus open surgery for colon cancer: long- term outcome of a randomised clinical trial. Lancet Oncol 2009;10:44-52. [PubMed] [Google Scholar]

9. Jobsen J, Aarts MJ, Siesling S, et al. Use of primary radiotherapy for rectal cancer in The Netherlands between 1997 and 2008: a population- based study. Clin Oncol (R Coll Radiol) 2012;24:e1-8. [PubMed] [Google Scholar]

10. Smith JJ, Garcia- Aguilar J. Advances and challenges in treatment of locally advanced rectal cancer. J Clin Oncol 2015;33:1797-808. [PMC free article] [PubMed] [Google Scholar]

11. Andre T, Boni C, Navarro M, et al. Improved overall survival with oxaliplatin, fluorouracil, and leucovorin as adjuvant treatment in stage II or III colon cancer in the MOSAIC trial. J Clin Oncol 2009; 27:3109-16. [PubMed] [Google Scholar]

12. Verhoeff SR, van Erning FN, Lemmens VE, et al. Adjuvant chemotherapy is not associated with improved Survival for all high- risk factors in stage II colon cancer. Int J Cancer 2016;139:187-93. [PubMed] [Google Scholar].
13. van der Pool A, Damhuis RA, IJzermans $\mathrm{JN}$, et al. Trends in incidence, treatment and Survival of patients with stage IV colorectal cancer: a population- based series. Color Dis 2012;14:56-61. [PubMed] [Google Scholar]. 